\title{
Factors Influencing Activities of Daily Living in Subjects With COPD
}

\author{
Ismail Ozsoy, Buse Ozcan Kahraman, Serap Acar, Sevgi Ozalevli, Atila Akkoclu, and Sema Savci
}

\begin{abstract}
BACKGROUND: Activities of daily living (ADL) are important for an independent life. As COPD progresses, the ability to complete ADL is usually reduced. Knowing the possible factors that influence the ability to perform ADL may allow better targeting of appropriate rehabilitation programs to increase the independence levels and/or to prevent further decreases in patients with COPD. Therefore, the aim of this study was to investigate ADL performance as measured by the London Chest Activity of Daily Living scale, which is a commonly used measure in patients with COPD. METHODS: This cross-sectional study included 44 clinically stable subjects who were not taking antibiotics and had not made any changes in their medications for at least three weeks with a COPD diagnosis based on Global Initiative for Chronic Obstructive Lung Disease. Demographic characteristics, pulmonary function, ADL measured by the London Chest Activity of Daily Living scale, functional exercise capacity via the 6-min walk distance, disease-related symptoms measured by the COPD Assessment Test, and peripheral and respiratory muscle strength were evaluated. A multiple linear regression (stepwise) analysis was used to determine the variables that have the greatest influence on ADL (ie, the London Chest Activity of Daily Living scale score). RESULTS: The London Chest Activity of Daily Living scale score had moderate correlations with the COPD Assessment Test score $(\mathrm{r}=0.31, P=.041)$, maximum expiratory pressure value $(\mathrm{r}=-0.37$, $P=.01), 6$-min walk distance $(\mathrm{r}=-0.48, P=.001)$, knee extensor muscle strength $(\mathrm{r}=-0.47$, $P=.001)$, handgrip strength $(\mathrm{r}=-0.44, P=.003)$. The 6-min walk distance, COPD Assessment Test score and maximal expiratory pressure values were significant and independent determinants of the London Chest Activity of Daily Living scale, with $40.1 \%$ of the variance in subjects with COPD. CONCLUSIONS: Functional exercise capacity, disease-related symptoms, and expiratory muscle strength have the greatest influence on ADL in the subjects with COPD. The level of independence to perform ADL can be increased by improving functional exercise capacity, reducing symptoms, and increasing expiratory muscle strength in subjects with COPD. Key words: COPD; activities of daily living; ADL; functional exercise capacity; disease-related symptoms; muscle strength. [Respir Care 2019;64(2):189-195. (C) 2019 Daedalus Enterprises]
\end{abstract}

\section{Introduction}

COPD, which is a treatable and preventable disease, is one of the most important causes of mortality and mor-

Dr Ozsoy is affiliated with School of Physical Therapy and Rehabilitation, Kırsehir Ahi Evran University, Kırsehir, Turkey. Drs Ozcan Kahraman, Acar, Ozalevli and Savci are affiliated with School of Physical Therapy and Rehabilitation, Dokuz Eylül University, Izmir, Turkey. Dr Akkoclu is affiliated with Department of Chest Diseases, Faculty of Medicine, Dokuz Eylül University, Izmir, Turkey.

The study was performed at the Dokuz Eylul University School of Physical Therapy and Rehabilitation in Izmir, Turkey. bidity. ${ }^{1}$ Although COPD mainly influences the pulmonary system, it may cause several systemic manifestations. ${ }^{2}$ Functional impairment and limitations in activities of daily living (ADL) are frequent in patients with COPD. Functional status can be defined as the ability to fulfill ADL. ${ }^{3}$ Functional impairment was found as a predictor of exac-

\footnotetext{
Dr Ozcan Kahraman presented a version of this paper at the Annual Congress of the European Respiratory Society, held 3-7 September 2016, in London, England.
}

The authors have disclosed no conflicts of interest. 
erbations and mortality. ${ }^{4,5} \mathrm{ADL}$, such as eating, walking, dressing, and bathing, are important for an independent life. ${ }^{6}$ As COPD progresses, the ability to complete ADL is usually reduced. ${ }^{7}$ Physiologic limitations, especially ventilatory insufficiency, have an important role in ADL impairment in patients with COPD. ${ }^{8}$ There is research that dynamic hyperinflation occurs after completing general ADL in subjects with moderate-to-severe COPD. ${ }^{9}$ Symptoms, especially dyspnea, cause reductions in ADL, and this situation leads to dependence and disability. ${ }^{10,11}$

Knowing the possible factors that influence the performance of ADL will assist with targeting appropriate rehabilitation programs to increase independence levels and/or prevent further declines in patients with COPD. A number of studies have sought to determine the correlation of variables that may influence the performance of ADL in subjects with COPD, ${ }^{7,12,13}$ yet, which variables have the greatest influence on ADL is still unclear. Questionnaires and scales are the most commonly used methods for evaluating ADL limitations. ${ }^{14}$ The London Chest Activity of Daily Living scale is a valid and reliable tool currently used in the evaluation of ADL in patients with COPD. ${ }^{15}$ Therefore, the aim of this study was to investigate the factors that influence ADL measured by the London Chest Activity of Daily Living scale in subjects with COPD.

\section{Methods}

\section{Study Design and Subjects}

The study design was cross-sectional. Forty-four clinically stable subjects who were not taking antibiotics and had not made any changes in their medications for at least three weeks with a diagnosis of COPD according to the Global Initiative for Chronic Obstructive Lung Disease (GOLD) (GOLD I $[n=3]$, GOLD II [ $n=21]$, GOLD III $[n=15]$, and GOLD IV $[n=5])$ participated in the study. ${ }^{1}$ Patients who were clinically unstable or who had cardiovascular, musculoskeletal, or neurologic disease that might influence assessments were excluded from the study. All the participants provided written consent to participate in the study, which was approved by the ethics committee of Dokuz Eylül University.

Correspondence: Ismail Ozsoy, School of Physical Therapy and Rehabilitation, Kırsehir Ahi Evran University, Kusdili Mahallesi, Sehit Coskun Tas Caddesi, No:2, Kırsehir, Turkey. E-mail: ozsoy.ismail@yahoo.com.

DOI: $10.4187 /$ respcare.05938

\section{QUICK LOOK}

\section{Current knowledge}

Activities of daily living (ADL), such as eating, walking, dressing, and bathing, are important for leading an independent life. As COPD progresses, it usually decreases patients' ability to perform ADL.

\section{What this paper contributes to our knowledge}

We showed that functional exercise capacity, COPDrelated symptoms, and expiratory muscle strength had the greatest influence on ADL in subjects with COPD. The level of independence needed to perform ADL can be increased by improving functional exercise capacity, reducing symptoms, and increasing expiratory muscle strength in subjects with COPD.

\section{Measurements}

The evaluations were carried out in $2 \mathrm{~d}$. In particular, muscle strength tests and exercise capacity tests were conducted on separate days.

\section{Pulmonary Function}

Spirometry (Sensor Medics Vmax 22, SensorMedics, Anaheim, California) was used to assess pulmonary function according to published guidelines by American Thoracic Society/European Respiratory Society. ${ }^{16}$

\section{Symptom Assessment}

The COPD Assessment Test was used to assess symptoms in subjects with COPD. The COPD Assessment Test is a reliable and valid method to assess the impact of COPD on a patient's health status. ${ }^{1}$ The COPD Assessment Test has 8 items related to COPD symptoms. The score ranges from 0 to 40 , and high scores indicate increased symptoms. ${ }^{1}$

\section{Respiratory Muscle Strength}

Maximal inspiratory pressure $\left(\mathrm{P}_{\mathrm{Imax}}\right)$ and maximal expiratory pressure $\left(\mathrm{P}_{\mathrm{Emax}}\right)$ were performed to assess respiratory muscle strength (Sensormedics Vmax 22). The subjects performed $3-5$ acceptable and reproducible maximal maneuvers (ie, differences of $\leq 10 \%$ between values). The recorded value was the highest value unless this was obtained from the last effort. ${ }^{17}$ The percentage of normal values by age and sex were used to interpret measurements. ${ }^{18}$ 


\section{Functional Exercise Capacity}

The 6-min walk test (6MWT) was performed to assess functional exercise capacity according to American Thoracic Society guidelines. ${ }^{19}$ Assessments of blood pressure (Erka Manual Sphygmomanometer, Bad Toelz, Germany), heart rate (Beurer pulse oximeter, Ulm, Germany), oxygen saturation (Beurer pulse oximeter, Ulm, Germany), and dyspnea and fatigue (modified Borg scale) were recorded before and after the 6MWT.

\section{Peripheral Muscle Strength}

Handgrip and knee extensor strength were assessed by using a handgrip dynamometer (Jamar dynamometer, Patterson Medical, Warrenville, Illinois) and a hand-held dynamometer (JTECH, Medical Commander Powertrack II, Salt Lake City, Utah), respectively. ${ }^{20,21}$ The hand-held dynamometry has good reliability (intraclass correlation coefficient, 0.84-0.87) and is suitable for measuring mean changes in muscle force generation for groups of people with COPD. ${ }^{22,23}$ Measurements were repeated 3 times in the dominant limbs, and average values were recorded.

\section{ADL}

The London Chest Activity of Daily Living scale is a valid, reliable, simple, and short disease-specific scale used to assess breathlessness during ADL in patients with COPD. ${ }^{15}$ The London Chest Activity of Daily Living scale is a commonly used measure, with many language validation studies. ${ }^{12,22-25}$ It has 15 items related to 4 domains, including self-care, domestic, physical, and leisure. Each item score ranges from 0 to 5 (the total score ranges from 0 to 75 ), and higher scores show increased limitation during ADL. ${ }^{15}$

\section{Statistical Analysis}

The IBM SPSS Statistics for Windows software v. 20.0 (IBM, Armonk, New York) was used to analyze the data. Skewness and Kurtosis tests were used to check normality. ${ }^{26}$ Parametric analysis was used because of the normally distributed data. Values are expressed as mean \pm SD for continuous variables, and number was reported for categorical variables. The Pearson product-moment correlation coefficients were used to examine the correlations between the London Chest Activity of Daily Living scale and other variables. Correlation coefficients of $>0.5$ were considered as a strong correlation, $0.3-0.5$ as a moderate correlation, and $0.2-0.3$ as a weak correlation. ${ }^{27}$ The level of significance was set at $P<.05$. Stepwise multiple linear regression analysis was used to determine the variables that had the greatest influence on the London Chest
Activity of Daily Living scale score. Significantly correlated variables (COPD Assessment Test, $\mathrm{P}_{\text {Emax }}$, 6MWT, handgrip strength, and knee extensor muscle strength) with the London Chest Activity of Daily Living scale scores were included in the regression model. In addition, the regression equation formula of the study was calculated.

To date, to our knowledge, the possible factors that influence the London Chest Activity of Daily Living scale have not been investigated. Nevertheless, a previous study showed that age is a significant determinant of ADL performance in elderly people $\left(\mathrm{R}^{2}=0.176, P<.05\right) .{ }^{28}$ Based on the findings of that study, the minimum required sample size for a multiple linear regression analysis was calculated as 40 participants for the probability level of .05; for the 8 determinants (age, $\mathrm{FEV}_{1} \%$ predicted, COPD Assessment Test score, $\mathrm{P}_{\text {Imax }}, \mathrm{P}_{\text {Emax }}, 6 \mathrm{MWT}$ distance [6MWD], knee extensor muscle, and handgrip strength) in the model, the anticipated effect size as 0.213 ; and a statistical power level of $80 \%$ when using G*Power Software (version 3.1.9.2). ${ }^{29}$

\section{Results}

Forty-four subjects completed the assessments. The characteristics of the subjects are presented in the Table 1. The London Chest Activity of Daily Living scale score had moderate correlation with COPD Assessment Test score $(\mathrm{r}=0.31, P=.041), \mathrm{P}_{\text {Emax }}(\mathrm{r}=-0.37, P=.01)$, 6MWD ( $\mathrm{r}=-0.48, P=.001)$, knee extensor muscle strength $(\mathrm{r}=-0.47, P=.001)$, and handgrip strength ( $\mathrm{r}=-0.44, P=.003)$ (Table 2). The COPD Assessment Test score, $\mathrm{P}_{\text {Emax }}, 6 \mathrm{MWD}$, knee extensor muscle strength, and handgrip strength were included as independent variables in the regression model to determine the possible determinants of London Chest Activity of Daily Living scale score.

Stepwise multiple linear regression analysis demonstrated that the 6MWD, COPD Assessment Test score, and $\mathrm{P}_{\mathrm{Emax}}$ were significant and independent determinants of the London Chest Activity of Daily Living scale score in subjects with COPD, with $40.1 \%$ of the variance (Table 3 and Fig. 1). The regression equation formula of the dependent variable (London Chest Activity of Daily Living scale score) was calculated by using explanatory variables (6MWD, COPD Assessment Test score, and $\mathrm{P}_{\text {Emax }}$ ) and coefficients (Table 3 ). The regression equation formula was London Chest Activity of Daily Living scale score $=36.52+(-0.04 \times 6 \mathrm{MWD})+(0.72 \times \mathrm{COPD}$ Assessment Test score $)+\left(-0.12 \times \mathrm{P}_{\text {Emax }}\right)$.

\section{Discussion}

The main finding of the study demonstrated that 6MWD, COPD Assessment Test score, and $\mathrm{P}_{\text {Emax }}$ had the greatest influence on ADL performance in subjects with COPD, 
Table 1. Subjects' Characteristics

\begin{tabular}{|c|c|}
\hline Characteristics & Result \\
\hline Age, mean \pm SD y & $66.4 \pm 9.2$ \\
\hline $\mathrm{BMI}$, mean $\pm \mathrm{SD} \mathrm{kg} / \mathrm{m}^{2}$ & $26.4 \pm 3.4$ \\
\hline \multicolumn{2}{|l|}{ GOLD stage, $n$} \\
\hline I & 3 \\
\hline II & 21 \\
\hline III & 15 \\
\hline IV & 5 \\
\hline $\mathrm{FEV}_{1}$, mean $\pm \mathrm{SD} \%$ predicted & $53.4 \pm 17.9$ \\
\hline $\mathrm{FVC}$, mean $\pm \mathrm{SD} \%$ predicted & $71.1 \pm 18.5$ \\
\hline $\mathrm{FEV}_{1} / \mathrm{FVC}$, mean $\pm \mathrm{SD}$ & $57.7 \pm 8.7$ \\
\hline $\mathrm{PEF}$, mean $\pm \mathrm{SD} \%$ predicted & $55.4 \pm 17.1$ \\
\hline $\mathrm{FEF}_{25-75}$, mean $\pm \mathrm{SD} \%$ predicted & $24.0 \pm 11.7$ \\
\hline $\mathrm{CAT}$ score, mean $\pm \mathrm{SD}$ & $10.7 \pm 3.2$ \\
\hline $6 \mathrm{MWD}$ mean $\pm \mathrm{SD}, \mathrm{m}$ & $411.1 \pm 64.6$ \\
\hline $\mathrm{P}_{\text {Imax }}$, mean $\pm \mathrm{SD} \mathrm{cm} \mathrm{H} \mathrm{H}_{2} \mathrm{O}$ & $61.8 \pm 26.3$ \\
\hline$\% \mathrm{P}_{\text {Imax }}$, mean $\pm \mathrm{SD}$ & $63.7 \pm 25.4$ \\
\hline $\mathrm{P}_{\text {Emax }}$, mean $\pm \mathrm{SD} \mathrm{cm} \mathrm{H} \mathrm{H}_{2} \mathrm{O}$ & $74.8 \pm 6.2$ \\
\hline $\mathrm{P}_{\text {Emax }}$, mean $\pm \mathrm{SD} \%$ & $40.5 \pm 9.4$ \\
\hline Knee extensor muscle strength, mean $\pm \mathrm{SD} \mathrm{kg}$ & $30.5 \pm 5.6$ \\
\hline Handgrip strength, mean $\pm \mathrm{SD} \mathrm{kg}$ & $32.4 \pm 7.2$ \\
\hline LCADL score, mean $\pm \mathrm{SD}$ & $19.1 \pm 6.1$ \\
\hline \multicolumn{2}{|l|}{$\overline{\mathrm{BMI}=\text { body mass index }}$} \\
\hline \multicolumn{2}{|l|}{ GOLD $=$ Global Initiative for Chronic Obstructive Lung Disease } \\
\hline \multicolumn{2}{|l|}{$\mathrm{PEF}=$ peak expiratory flow } \\
\hline \multicolumn{2}{|l|}{$\mathrm{FEF}_{25-75}=$ forced expiratory flow at $25-75 \%$} \\
\hline \multicolumn{2}{|l|}{$\begin{array}{l}\mathrm{CAT}=\text { COPD Assessment Test } \\
\text { 6MWD }=6 \text {-min walk test distance }\end{array}$} \\
\hline \multirow{2}{*}{\multicolumn{2}{|c|}{$\begin{array}{l}6 \mathrm{MWD}=6 \text {-min walk test distance } \\
\mathrm{P}_{\mathrm{Im}}=\text { maximal inspiratory pressure }\end{array}$}} \\
\hline & \\
\hline $\mathrm{P}_{\text {Emax }}=$ maximal expiratory pressure & \\
\hline LCADL $=$ London Chest Activity of Daily Living scale & \\
\hline
\end{tabular}

Table 2. Correlation Between LCADL Score and Other Parameters

\begin{tabular}{lcl}
\hline \hline \multicolumn{1}{c}{ Parameter } & $\mathrm{r}^{*}$ & $P$ \\
\hline Age, y & 0.004 & .98 \\
FEV $_{1}, \%$ predicted & -0.28 & .07 \\
CAT score $(0-40)$ & 0.31 & .041 \\
$\mathrm{P}_{\text {Imax }}, \mathrm{cm} \mathrm{H}_{2} \mathrm{O}$ & -0.19 & .23 \\
$\mathrm{P}_{\text {Imax }}, \%$ & -0.04 & .82 \\
$\mathrm{P}_{\text {Emax }}, \mathrm{cm} \mathrm{H}_{2} \mathrm{O}$ & -0.37 & .01 \\
$\mathrm{P}_{\text {Emax }}, \%$ & -0.06 & .72 \\
6MWD, m & -0.48 & .001 \\
Knee extensor muscle strength, $\mathrm{kg}$ & -0.47 & .001 \\
Handgrip strength, kg & -0.44 & .003
\end{tabular}

* Pearson product moment correlation coefficient.

LCADL $=$ London Chest Activity of Daily Living scale

CAT $=$ COPD Assessment Test

$\mathrm{P}_{\text {Imax }}=$ maximal inspiratory pressure

$\mathrm{P}_{\text {Emax }}=$ maximal expiratory pressure

$6 \mathrm{MWD}=6$-min walk test distance

with these variables explaining $40.1 \%$ of the variance in the London Chest Activity of Daily Living scale. In addition, the study demonstrated that the London Chest Activ-
Table 3. Stepwise Multiple Linear Regression Model of Activities of Daily Living

\begin{tabular}{|c|c|c|c|c|}
\hline Variable & B & SE & $\beta$ & $P$ \\
\hline Constant & 36.52 & 5.39 & NA & $<.001$ \\
\hline 6MWD, m & -0.04 & 0.01 & -0.41 & .002 \\
\hline CAT score & 0.72 & 0.22 & 0.39 & .002 \\
\hline $\mathrm{P}_{\text {Emax }}, \mathrm{cm} \mathrm{H}_{2} \mathrm{O}$ & -0.12 & 0.045 & -0.33 & .01 \\
\hline $\begin{array}{l}\mathrm{r}=0.67 ; \mathrm{R}^{2}=0.44 \\
\mathrm{~B}=\text { unstandardized } \mathrm{r} \\
\mathrm{NA}=\text { not applicable } \\
\mathrm{SE}=\text { standard error } \\
6 \mathrm{MWD}=6 \text {-min wal } \\
\mathrm{CAT}=\text { COPD Asses } \\
\mathrm{P}_{\mathrm{Emax}}=\text { maximal exp }\end{array}$ & $\begin{array}{l}\mathrm{R}^{2}=0.40 \\
\text { coefficier } \\
\text { tance } \\
\text { est } \\
\text { ressure }\end{array}$ & 001). & & \\
\hline
\end{tabular}

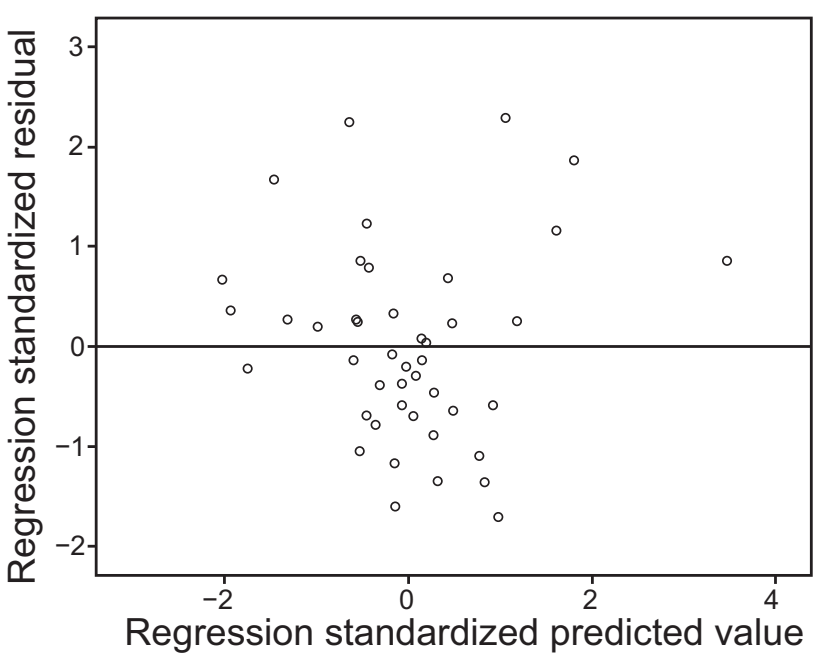

Fig. 1. Scatter plot graphic of the regression model to determine daily living activities.

ity of Daily Living scale was correlated with peripheral muscle strength.

The 6MWT is inexpensive, reliable, and commonly used to assess functional capacity in patients with COPD. ${ }^{30}$ The 6MWD is used as a marker of many parameters in these patients. Previous studies showed that the 6MWT is a predictor of nocturnal oxygen desaturation, ${ }^{31}$ physical activity, ${ }^{32}$ and mortality ${ }^{33}$ in subjects with COPD. In addition, our study showed that $6 \mathrm{MWD}$ is a factor that influences ADL. This finding indicated that subjects with COPD with good functional exercise capacity would experience fewer limitations in fulfilling their ADL.

Dyspnea, cough, and sputum production are characteristic features of COPD. ${ }^{1}$ As COPD progresses, ventilatory limitations occur. Lahaije et $\mathrm{al}^{8}$ showed that ventilatory limitations have an important role in the decline of ADL performance. Symptoms, especially dyspnea, limit exercise capacity as well as ADL ability. ${ }^{34}$ The COPD Assessment Test is a suggested and comprehensive assessment 
for symptoms in subjects with COPD. ${ }^{1}$ Our study showed that the COPD Assessment Test score was a factor that influences the performance of ADL. Programs for symptom management in patients with COPD may increase participation in daily life and independence.

Systemic changes, for example, expiratory muscle weakness with alterations in muscle structure, are found in patients with COPD. ${ }^{35}$ Early signs of fatigue and decreased endurance typically occur in expiratory muscles of patients with COPD. ${ }^{36}$ Singer et $\mathrm{al}^{37}$ showed that reduced muscle strength is associated with decreased functional capacity, and muscle weakness is an important factor for disability in subjects with COPD. In addition, dyspnea, one of the most important consequences of imbalance between respiratory muscle strength and load, ${ }^{38}$ is an important factor for limitations in ADL. ${ }^{10}$ Khalil et al ${ }^{39}$ showed that the $\mathrm{P}_{\mathrm{Emax}}$ is correlated with dyspnea and functional exercise capacity. Expiratory muscle strength was found as a factor that influences ADL in subjects with COPD. Participation in ADL can be increased by improving expiratory muscle strength.

Exercise intolerance and dyspnea limit ADL in patients COPD. ${ }^{10}$ Previous studies showed that respiratory muscle weakness caused exercise intolerance and dyspnea. ${ }^{37,40} \mathrm{In}$ addition, it was shown that dyspnea is reduced and exercise capacity is increased after inspiratory muscle training. ${ }^{41}$ Surprisingly, no significant association between inspiratory muscle strength and ADL was found in our study. We assumed that these findings were due to the high inspiratory muscle strength averages found in our subjects, with a mean $\mathrm{P}_{\text {Imax }}$ of $>60 \mathrm{~cm} \mathrm{H}_{2} \mathrm{O}$ as the cutoff value for respiratory muscle weakness. ${ }^{42}$ There may be a relationship between ADL and $\mathrm{P}_{\text {Imax }}$, depending on dyspnea and exercise intolerance that will develop in patients with inspiratory muscle weakness.

Peripheral muscle dysfunction is one of the well-known consequences of COPD. ${ }^{43}$ Previous studies demonstrated that peripheral muscle weakness is related to a shorter life expectancy, ${ }^{44}$ poor health-related quality of life, ${ }^{45}$ and exercise intolerance ${ }^{46}$ in patients with COPD. Our study showed that peripheral muscle strength was associated with ADL. As peripheral muscle strength increases, daily life activities may improve.

To determine the phase of airway obstruction and disease severity, $\mathrm{FEV}_{1}$ is used in patients with COPD. ${ }^{1} \mathrm{Si}$ mon et $\mathrm{al}^{7}$ showed a positive correlation between the $\mathrm{FEV}_{1} \%$ and ADL. Nevertheless, our study demonstrated that there was no correlation between $\mathrm{FEV}_{1} \%$ and ADL. This finding may be due to the low number of GOLD I group and GOLD IV group subjects with COPD. Studies that involve subjects with different degrees of airway obstruction may be helpful.

Liu et al ${ }^{47}$ showed that COPD is associated with mortality and disability in the elderly. Participation in ADL decreases in elderly subjects with COPD in this study. ${ }^{47}$ However, there was no association between age and ADL in our study. We believed that these results were found because the average age of the participants was $>65 \mathrm{y}$ (mean age, $66.4 \mathrm{y}$ ). More studies involving individuals with COPD in different age groups would be helpful.

There were some limitations of this study. First, although we had more than the minimum required sample size, the number of participants in the GOLD I and IV groups was low. In this respect, the study findings cannot be generalized to patients with COPD and different disease severity. Second, ADL were not compared with an age- and sex-matched healthy control group in the study. Including a healthy comparison group may provide a better perspective on whether the defined factors that influence ADL are only related to patients with COPD.

\section{Conclusions}

Functional capacity, COPD-related symptoms, and expiratory muscle strength have the greatest influence on ADL in subjects with COPD. The level of independence in ADL of subjects with COPD can be increased by improving functional exercise capacity and expiratory muscle strength, and reducing COPD-related symptoms. Further studies should investigate the effects of rehabilitation programs by targeting these factors on ADL in subjects with COPD.

\section{REFERENCES}

1. GOLD. Global Initiative for Chronic Obstructive Lung Disease. Global strategy for the diagnosis, management, and prevention of chronic obstructive pulmonary disease. https://goldcopd.org. Accessed December 20, 2017.

2. Patel AR, Hurst JR. Extrapulmonary comorbidities in chronic obstructive pulmonary disease: state of the art. Expert Rev Respir Med 2011;5(5):647-662.

3. Leidy NK. Functional status and the forward progress of merry-gorounds: toward a coherent analytical framework. Nurs Res 1994; 43(4):196-202.

4. Fan VS, Ramsey SD, Make BJ, Martinez FJ. Physiologic variables and functional status independently predict COPD hospitalizations and emergency department visits in patients with severe COPD. COPD 2007;4(1):29-39.

5. Pitta F, Troosters T, Probst VS, Spruit MA, Decramer M, Gosselink R. Physical activity and hospitalization for exacerbation of COPD. Chest 2006;129(3):536-544.

6. Pendleton HM, Schultz-Krohn W. Pedretti's occupational therapy: practice skills for physical dysfunction, 7th ed. St. Louis: Mosby; 2012:157-162.

7. Simon KM, Carpes MF, Correa KS, dos Santos K, Karloh M, Mayer AF. Relationship between daily living activities (ADL) limitation and the BODE index in patients with chronic obstructive pulmonary disease. Rev Bras Fisioter 2011;15(3):212-218.

8. Lahaije AJ, van Helvoort HA, Dekhuijzen PN, Heijdra YF. Physiologic limitations during daily life activities in COPD patients. Respir Med 2010;104(8):1152-1159. 


\section{FACTORS INFLUENCING ADL IN COPD}

9. Silva CS, Nogueira FR, Porto EF, Gazzotti MR, Nascimento OA, Camelier A, Jardim JR. Dynamic hyperinflation during activities of daily living in COPD patients. Chron Respir Dis 2015;12(3):189196.

10. Jolley CJ, Moxham J. A physiological model of patient-reported breathlessness during daily activities in COPD. Eur Respir Rev 2009; 18(112):66-79.

11. Cutaia M, Brehm R, Cohen M. The relationship of the BODE index to oxygen saturation during daily activities in patients with chronic obstructive pulmonary disease. Lung 2011;189(4):269-277.

12. Klijn P, Legemaat M, Beelen A, Keimpema A, Garrod R, Bergsma $\mathrm{M}$, et al. Validity, reliability, and responsiveness of the Dutch version of the London Chest Activity of Daily Living scale in patients with severe COPD. Medicine (Baltimore) 2015;94(49):e2191.

13. Carpes MF, Mayer AF, Simon KM, Jardim JR, Garrod R. The Brazilian Portuguese version of the London Chest Activity of Daily Living scale for use in patients with chronic obstructive pulmonary disease. J Bras Pneumol 2008;34(3):143-151.

14. Janaudis-Ferreira T, Beauchamp MK, Robles PG, Goldstein RS, Brooks D. Measurement of activities of daily living in patients with COPD: a systematic review. Chest 2014;145(2):253-271.

15. Garrod R, Bestall JC, Paul EA, Wedzicha JA, Jones PW. Development and validation of a standardized measure of activity of daily living in patients with severe COPD: the London Chest Activity of Daily Living scale (LCADL). Respir Med 2000;94(6):589-596.

16. Miller MR, Crapo R, Hankinson J, Brusasco V, Burgos F, Casaburi $\mathrm{R}$, et al; ATS/ERS Task Force. General considerations for lung function testing. Eur Respir J 2005;26(1):153-161.

17. Neder JA, Andreoni S, Lerario MC, Nery LE. Reference values for lung function tests. II. Maximal respiratory pressures and voluntary ventilation. Braz J Med Biol Res 1999;32(6):719-727.

18. Black LF, Hyatt RE. Maximal respiratory pressures: normal values and relationship to age and sex. Am Rev Respir Dis 1969;99(5):696702 .

19. Erratum: ATS Statement: Guidelines for the Six-Minute Walk Test. Am J Respir Crit Care Med 2016 May 15;193(10):1185.

20. Andrews AW, Thomas MW, Bohannon RW. Normative values for isometric muscle force measurements obtained with hand-held dynamometers. Phys Ther 1996;76(3):248-259.

21. Shechtman O, Gestewitz L, Kimble C. Reliability and validity of the DynEx dynamometer. J Hand Ther 2005;18(3):339-347.

22. Beaumont M, Couturaud F, Jego F, Pichon R, Le Ber C, Péran L, et al. Validation of the French version of the London Chest Activity of Daily Living scale and the Dyspnea-12 questionnaire. Int J Chron Obstruct Pulmon Dis 2018;13:1399-1405.

23. Choi JT, Seo JH, Ko MH, Park SH, Kim GW, Won YH. Validation of Korean version of the London Chest Activity of Daily Living scale in patients with chronic obstructive pulmonary disease. Ann Rehabil Med 2018;42(2):329-335.

24. Pitta F, Probst VS, Kovelis D, Segretti NO, Mt Leoni A, Garrod $\mathrm{R}$, Brunetto AF. [Validation of the Portuguese version of the London Chest Activity of Daily Living Scale (LCADL) in chronic obstructive pulmonary disease patients]. Rev Port Pneumol 2008; 14(1):27-47.

25. Met S. Determination of validity and reliability of London Chest Activity of Daily Living scale and physical activity level in obstructive lung disease [master's thesis]. Ankara, Turkey: Hacattepe University; 2009.

26. Field A. Discovering statistics using SPSS for Windows: Advanced techniques for beginners (Introducing Statistical Methods series). London: SAGE publications Ltd; 2000:46-48.

27. Cohen J. Statistical power analysis for the behavioural sciences, 2nd Edition. Hillsdale, New Jersey: Lawrence Earlbaum; 1988:109-116.
28. Connolly D, Garvey J, McKee G. Factors associated with ADL/IADL disability in community dwelling older adults in the Irish longitudinal study on ageing (TILDA). Disabil Rehabil 2017;39(8): 809-816.

29. Faul F, Erdfelder E, Lang A-G, Buchner A. G* Power 3: A flexible statistical power analysis program for the social, behavioral, and biomedical sciences. Behav Res Methods. 2007;39(2):175191.

30. Holland AE, Spruit MA, Troosters T, Puhan MA, Pepin V, Saey D, et al. An official European Respiratory Society/American Thoracic Society technical standard: field walking tests in chronic respiratory disease. Eur Respir J 2014;44(6):1428-1446.

31. Iliaz S, Cagatay T, Bingol Z, Okumus G, Iliaz R, Kuran G, et al. Does the 6-minute walk test predict nocturnal oxygen desaturation in patients with moderate to severe COPD? Chron Respir Dis 2015; 12(1):61-68.

32. Pitta F, Troosters T, Probst VS, Spruit MA, Decramer M, Gosselink R. Quantifying physical activity in daily life with questionnaires and motion sensors in COPD. Eur Respir J 2006;27(5): 1040-1055.

33. Polkey MI, Spruit MA, Edwards LD, Watkins ML, Pinto-Plata V, Vestbo J, et al; Evaluation of COPD Longitudinally to Identify Predictive Surrogate Endpoints (ECLIPSE) Study Investigators. Sixminute-walk test in chronic obstructive pulmonary disease: minimal clinically important difference for death or hospitalization. Am J Respir Crit Care Med 2013;187(4):382-386.

34. Hajiro T, Nishimura K, Tsukino M, Ikeda A, Oga T, Izumi T. A comparison of the level of dyspnea vs disease severity in indicating the health-related quality of life of patients with COPD. Chest 1999; 116(6):1632-1637.

35. Agustí AG. Systemic effects of chronic obstructive pulmonary disease. Proc Am Thorac Soc 2005;2(4):367-370; discussion 371362.

36. Ramírez-Sarmiento A, Orozco-Levi M, Barreiro E, Méndez R, Ferrer A, Broquetas J, Gea J. Expiratory muscle endurance in chronic obstructive pulmonary disease. Thorax 2002;57(2):132-136.

37. Singer J, Yelin EH, Katz PP, Sanchez G, Iribarren C, Eisner MD, Blanc PD. Respiratory and skeletal muscle strength in chronic obstructive pulmonary disease: impact on exercise capacity and lower extremity function. J Cardiopulm Rehabil Prev 2011;31(2): 111-119.

38. Marchand E, Decramer M. Respiratory muscle function and drive in chronic obstructive pulmonary disease. Clin Chest Med 2000;21(4): 679-692.

39. Khalil M, Wagih K, Mahmoud O. Evaluation of maximum inspiratory and expiratory pressure in patients with chronic obstructive pulmonary disease. Egypt J Chest Dis Tuberc 2014;63(2): 329-335.

40. Ferrari K, Goti P, Misuri G, Amendola M, Rosi E, Grazzini M, et al. Chronic exertional dyspnea and respiratory muscle function in patients with chronic obstructive pulmonary disease. Lung 1997;175(5): 311-319.

41. Sánchez Riera H, Montemayor Rubio T, Ortega Ruiz F, Cejudo Ramos P, Del Castillo Otero D, Elias Hernandez T, et al. Inspiratory muscle training in patients with COPD: effect on dyspnea, exercise performance, and quality of life. Chest 2001;120(3):748756.

42. Gosselink R, De Vos J, van den Heuvel SP, Segers J, Decramer M, Kwakkel G. Impact of inspiratory muscle training in patients with COPD: what is the evidence? Eur Respir J 2011;37(2): 416-425.

43. Gea J, Agusti A, Roca J. Pathophysiology of muscle dysfunction in COPD. J Appl Physiol (1985) 2013;114(9):1222-1234. 


\section{FACTORS INFLUENCING ADL IN COPD}

44. Swallow EB, Reyes D, Hopkinson NS, Man WD, Porcher R, Cetti EJ, et al. Quadriceps strength predicts mortality in patients with moderate to severe chronic obstructive pulmonary disease. Thorax 2007;62(2):115-120.

45. Mangueira NM, Viega IL, Mangueira Mde A, Pinheiro AN, Costa Mdo R. Correlation between clinical parameters and health-related quality of life in women with COPD. J Bras Pneumol 2009;35(3): 248-255.
46. Debigaré R, Maltais F. The major limitation to exercise performance in COPD is lower limb muscle dysfunction. J Appl Physiol (1985) 2008;105(2):751-753; discussion 755-757.

47. Liu Y, Croft JB, Anderson LA, Wheaton AG, Presley-Cantrell LR, Ford ES. The association of chronic obstructive pulmonary disease, disability, engagement in social activities, and mortality among US adults aged 70 years or older, 1994-2006. Int J Chron Obstruct Pulmon Dis 2014;9:75-83. 